\title{
Circuit
}

Musiques contemporaines

\section{Qu'est-ce que ça veut dire, musique actuelle?}

\section{Jean Derome}

Volume 6, numéro 2, 1995

Musique actuelle?

URI : https://id.erudit.org/iderudit/902130ar

DOI : https://doi.org/10.7202/902130ar

Aller au sommaire du numéro

Éditeur(s)

Les Presses de l'Université de Montréal

ISSN

1183-1693 (imprimé)

1488-9692 (numérique)

Découvrir la revue

Citer cet article

Derome, J. (1995). Qu'est-ce que ça veut dire, musique actuelle? Circuit, 6(2), 15-18. https://doi.org/10.7202/902130ar d'utilisation que vous pouvez consulter en ligne.

https://apropos.erudit.org/fr/usagers/politique-dutilisation/ 


\section{Qu'est-ce que ca veut dire, musique actuelle? \\ Jean Derome}

À ma connaissance, c'est le Festival international de musique actuelle de Victoriaville ${ }^{(1)}$ qui a créé l'appellation musique "actuelle». Au début, je ne savais pas ce que ce mot pouvait vouloir dire et je crois que c'est par sa programmation même que le festival a délimité le sens que ce mot peut prendre. Décrire ce festival, c'est décrire la musique actuelle.

Le cœur du courant de musique actuelle est constitué par tous ces inclassables, dont la musique est à l'intersection d'influences et de styles connus, ces apatrides qu'on ne saurait faire figurer uniquement dans un style ou l'autre. II n'appartiennent ni à la « New Music », ni à la musique « contemporaine», ni au jazz "moderne ", ni au "Art » rock, ni à la "musique improvisée européenne ", mais un peu à tout cela. Musique actuelle veut dire musique métisse.

Ce festival ne se cantonne pas dans un style. La seule constante de sa programmation, finalement, est l'actualité. De plus, il traite toutes les tendances différentes avec un égal respect, ce qui constitue à mon avis un de ses atouts majeurs. Nous vivons une époque où survivent et cohabitent une grande quantité de genres musicaux qui peuvent tous à part entière être considérés comme de l'Art lpar opposition au monde du commercialisme et de l'Entertainement?), mais il est rare de retrouver toutes ces tendances dans une même programmation.

Ce foisonnement de styles semble faire problème pour bien des gens, peutêtre parce que nous manquons de mots pour définir la musique, contrairement aux arts visuels où, indépendamment des écoles stylistiques, on a aussi des méthodes de production bien établies : peinture, sculpture, gravure, collage, photographie, vidéo, cinéma, etc. On ne peut demander à un médium particulier d'atteindre les mêmes objectifs qu'un autre malgré le fait qu'il existe des règles fondamentales (de composition, par exemple) applicables à tous les arts visuels. On ne reproche pas à l'aquarelle d'être flove, à la photographie d'être un art de l'instant, à la sculpture d'être en trois dimensions.
11) Le FIMAV, qui en est, en mai 1995 , à sa douzième édition, est un des plus importants festivals de musique actuelle au monde. 
En musique, par contre, on s'étonne de voir des journalistes et des théoriciens s'attendre à ce que toutes les musiques répondent aux exigences d'une musique particulière. Par exemple, on nous présente souvent la musique contemporaine comme l'élite de l'élite. Comme si les interprètes et les compositeurs de musique contemporaine pouvaient tout jover, tout composer; or, croyez-moi, les musiciens classiques et contemporains font assez souvent horriblement pitié lorsqu'ils s'aventurent hors de leur discipline.

La musique n'est pas une pyramide dont la musique contemporaine serait le sommet. La musique est plutôt un terrain que certains musiciens choisissent d'explorer dans son entièreté pendant que d'autres préfèrent cultiver un tout petit lopin. II n'appartient à personne de juger de ces choix. J'aimerais simplement que l'on considère l'ensemble des musiques vivantes de manière plus ouverte et sans jugements de valeur.

Une deuxième forte tendance de la musique actuelle, telle que définie par le FIMAV, est que la distinction entre interprète, compositeur et improvisateur tend à s'abolir. N'est-il pas grand temps de sortir de cette division des tâches typique de la musique romantique et de l'ère industrielle? Les ensembles de musique actuelle fonctionnent généralement suivant le modèle des groupes de musique populaire. En fait, ce sont des groupes de musique populaire.

Un renouveau en musique ne pourra venir que des interprètes, des joveurs. II faudrait qu'ils reprennent en main leur droit de décider de ce qu'ils ont à jover et de quelle manière ils vont s'y prendre. Il faudrait qu'ils composent, qu'ils improvisent, qu'ils s'impliquent à tous les niveaux, qu'ils refusent de jouer ce qu'ils n'aiment pas, qu'ils se passionnent pour ce qu'ils font ou qu'ils abandonnent carrément.

\section{De l'utilisation abusive du terme}

On peut supposer que le fait que de plus en plus de gens utilisent le mot "musique actuelle" pour définir ce qu'ils font est un hommage direct à la vivacité et au dynamisme de l'organisation du FIMAV. Depuis quelques années, je me surprends à répondre "musique actuelle » aux gens qui me demandent ce que je fais, mais je ne sais pas si j'oserai encore longtemps utiliser un vocable pareil, d'autant que de plus en plus de musiciens, d'organisateurs et de diffuseurs se sont emparés du nom pour en utiliser le pouvoir. Utiliser un nom comme raccourci pour la pensée est une chose bien compréhensible (et c'est probablement la base du langage), mais l'utiliser comme 
une arme, pour le pouvoir que ce mot confère, en est un autre. Tout le monde s'accroche à un mot dont la cote monte en bourse sans vouloir lâcher sa grande réputation et son petit marché.

Je dois avover que c'est spécialement l'utilisation de plus en plus exclusive de l'expression « musique actuelle » par le monde de la musique contemporaine qui me donne le plus d'urticaire. Le mot s'appauvrit s'il sert davantage à exclure qu'à inclure. Mais que se passe til donc en musique contemporaine? Ce n'est pas en changeant son nom qu'on va faire refleurir l'arbre qui nous a déjà donné de si beaux fruits. Musique contemporaine et musique actuelle ne sauraient aucunement être considérées comme synonymes et je considère cette « tentative de vol » comme un aveu d'essoufflement en même temps que la reconnaissance de l'attrait qu'exerce la musique actuelle sur les musiques plus institutionnalisées.

Si partager une bannière collective pendant quelques années a pu me réjouir et me réchauffer le cœur, i'étais quand même plutôt heureux dans les limbes de l'« Inclassable " et j'entends bien y retourner assez vite si on tourmente encore trop longtemps le pauvre mot. Je laisserai sans regret ce poids épouvantable de l'Histoire qui va de pair avec les définitions et qui est en train d'étouffer toute spontanéité et toute invention dans les styles classés.

Qu'allons-nous faire de tout ces mots qui s'accumulent entre nous et la chose et qui nous en éloignent de plus en plus? 
